\title{
Effect of Pre-oxidation on High Temperature Sulfidation \\ Behavior of FeCr and FeCrAl Alloys
}

\author{
Marina Fuser Pillis, Lalgudi Venkataraman Ramanathan* \\ Instituto de Pesquisas Energéticas e Nucleares, Comissão Nacional de Energia Nuclear, \\ Travessa R no 400, 05508-000 Cidade Universitária - SP, Brazil
}

Received: September 2, 2002; Revised: September 4, 2002

\begin{abstract}
High temperature corrosion of structural alloys in sulfur bearing environments is many orders of magnitude higher than in oxidizing environments. Efforts to increase sulfidation resistance of these alloys include addition of alloying elements. Aluminum additions to iron-chromium alloys bring about increase in sulfidation resistance. This paper reports the effect of pre-oxidation on the sulfidation behavior of $\mathrm{Fe}-20 \mathrm{Cr}$ and $\mathrm{Fe}-20 \mathrm{Cr}-5 \mathrm{Al}$ alloys in $\mathrm{H}_{2}-2 \% \mathrm{H}_{2} \mathrm{~S}$ environment at $800{ }^{\circ} \mathrm{C}$. The surfaces of sulfidized specimens were also examined. Pre-oxidation of the two alloys results in an incubation period during subsequent sulfidation. After this incubation period, the $\mathrm{Fe}-20 \mathrm{Cr}$ alloy showed sulfidation behavior similar to that when the alloy was not pre-oxidized. The incubation period during sulfidation of the $\mathrm{Fe}-20 \mathrm{Cr}-5 \mathrm{Al}$ alloy was significantly longer, over $45 \mathrm{~h}$, compared to $2 \mathrm{~h}$ for the $\mathrm{Al}$ free alloy. Based on the microscopic and gravimetric data a mechanism for sulfidation of these alloys with pre-oxidation has been proposed.
\end{abstract}

Keywords: Sulfidation, iron-chromium alloy, iron-chromium-aluminium alloy, pre-oxidation

\section{Introduction}

The resistance of structural alloys to rapid degradation in aggressive environments at elevated temperatures usually depends on the ability of the alloys to form and maintain a protective reaction product scale. In most oxidizing environments, $\mathrm{Cr}_{2} \mathrm{O}_{3}$ is the predominant constituent of the scale on chromium containing iron based alloys. These have been the main alloys used in elevated temperature applications and in regions of coal gasification and petrochemical processes. The gas environments in these processes are, in general, complex multi-component mixtures that contain sulfur bearing gases $\left(\mathrm{H}_{2} \mathrm{~S}\right.$ and $\left.\mathrm{SO}_{2}\right)$ in addition to oxidants $\left(\mathrm{CO}_{2} / \mathrm{CO}\right.$ and $\left.\mathrm{H}_{2} \mathrm{O} / \mathrm{H}_{2}\right)$. High temperature corrosion of various metals and alloys in sulfur bearing environments is many orders of magnitude higher than their oxidation rates ${ }^{1-4}$. This difference is mainly attributed to the nature of the sulfide scale, which is non-adherent and highly porous, whereas the oxide scale is compact and adherent to the substrate ${ }^{5-8}$.

Despite significant efforts during the last 15 years, the sulfidation mechanism is still not adequately explained. The very large number of transition metal sulfides compared to the corresponding oxides makes sulfidation studies more complicated. Sulfides are thermodynamically less stable, fuse at lower temperatures and reveal significant shifts in stoichiometry, compared to the corresponding oxides ${ }^{6}$.

A number of studies describe the behavior of $\mathrm{Fe}-\mathrm{Cr}$ alloys in $\mathrm{H}_{2} \mathrm{~S}-\mathrm{H}_{2}$ mixtures ${ }^{9-11}$. In all cases, $\mathrm{Cr}$ additions were reported to be beneficial. The nature of the products formed on the alloy surface depended on the $\mathrm{Cr}$ content. With less than $40 \% \mathrm{Cr}$, the scale was duplex, and consisted of $\mathrm{Fe}_{1-\mathrm{x}} \mathrm{S}$ in its external part and a mixture of $\mathrm{Fe}_{1-\mathrm{x}} \mathrm{S}-\mathrm{FeCr}_{2} \mathrm{~S}_{4}$ in its internal part. Addition of 3-5 wt.\% $\mathrm{Al}$ to $\mathrm{Fe}-17 \mathrm{Cr}$ alloys increased sulfidation resistance in $\mathrm{H}_{2} \mathrm{~S}$ environments with sulfur partial pressure $\left(\mathrm{Ps}_{2}\right)$ of $6 \times 10^{-2}$ torr $^{12}$. Further increase in $\mathrm{Al}$ content, as iron aluminides, increased sulfidation resistance even more at $800{ }^{\circ} \mathrm{C}$, and this was attributed to the formation of $\alpha-\mathrm{Al}_{2} \mathrm{O}_{3}$ scale. Addition of $\mathrm{Cr}$ as a ternary element to iron aluminides decreased sulfidation resistance.

In the light of the above contributions with respect to the effect of $\mathrm{Al}$ addition to $\mathrm{Fe}-\mathrm{Cr}$ alloys on sulfidation behavior, in this investigation the effect of pre-oxidation on

*e-mail: lalgudi@ipen.br

Presented at the International Symposium on High Temperature Corrosion in Energy Related Systems, Angra dos Reis - RJ, September 2002. 
the sulfidation behavior of $\mathrm{Fe}-20 \mathrm{Cr}$ and $\mathrm{Fe}-20 \mathrm{Cr}-5 \mathrm{Al}$ alloys in $\mathrm{H}_{2}-\mathrm{H}_{2} \mathrm{~S}$ environments at $800^{\circ} \mathrm{C}$, has been studied. The sulfide scales have been characterized and a mechanism for sulfide scale growth has been proposed.

\section{Methods and Materials}

Iron-chromium (FeCr) and Iron-chromium-aluminum ( $\mathrm{FeCrAl}$ ) alloy ingots with compositions as shown in Table 1 were prepared in a vacuum induction furnace. The ingots were hot forged at $980{ }^{\circ} \mathrm{C}$, specimens cut to size and ground to 220 mesh. The specimens were pre-oxidized in oxygen for $4 \mathrm{~h}$ at $1000{ }^{\circ} \mathrm{C}$ and then exposed to flowing $\mathrm{H}_{2}-2 \%$ $\mathrm{H}_{2} \mathrm{~S}$ in a thermobalance at $800{ }^{\circ} \mathrm{C}$. Heating to and cooling of the specimens from the test temperature was carried out in an argon atmosphere. The sulfur partial pressures during these tests were $10^{-8} \mathrm{~atm}$. Sulfidation kinetics of the alloys were determined from the mass gain $v s$. time curves.

The surfaces of specimens were examined in a scanning electron microscope and the composition of the reaction products determined using energy dispersive analysis (EDS) and X-ray diffraction analysis.

\section{Results and Discussion}

\subsection{Pre-oxidation of the alloys}

The two alloys were isothermally oxidized for $4 \mathrm{~h}$ at $1000{ }^{\circ} \mathrm{C}$ as these parameters correspond to a steady state

Table 1. Chemical composition of the two alloys

\begin{tabular}{lccr}
\hline Alloys & \multicolumn{3}{c}{ Elements } \\
\hline $\mathrm{FeCr}$ & $\mathrm{Cr}$ & $\mathrm{Al}$ & $\mathrm{Fe}$ \\
$\mathrm{FeCrAl}$ & 19.74 & - & balance \\
\hline
\end{tabular}

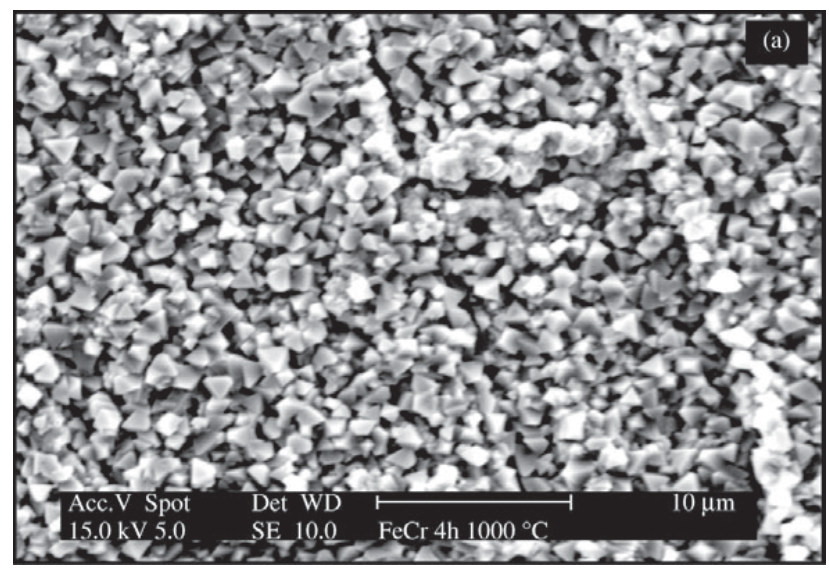

region in the parabolic oxidation mass gain vs. time curve of these alloys. Fig. 1 reveals the surfaces of the alloys oxidized for $4 \mathrm{~h}$ at $1000^{\circ} \mathrm{C}$. The oxides on the surface of $\mathrm{FeCr}$ alloy were found to be $\mathrm{Cr}_{2} \mathrm{O}_{3}$ and $\mathrm{FeCr}_{2} \mathrm{O}_{4}$ and that on the surface of FeCrAl alloy to be $\alpha-\mathrm{Al}_{2} \mathrm{O}_{3}, \theta-\mathrm{Al}_{2} \mathrm{O}_{3}, \mathrm{Cr}_{2} \mathrm{O}_{3}$ and $\mathrm{FeCr}_{2} \mathrm{O}_{4}$, as shown in the diffractograms in Fig.2.

\subsection{Sulfidation of pre-oxidized alloys}

The isothermal sulfidation curves of the two alloys preoxidized for $4 \mathrm{~h}$ at $1000{ }^{\circ} \mathrm{C}$ and sulfidized at $800{ }^{\circ} \mathrm{C}$ are shown in Fig. 3. To enable comparison, the figure also shows the sulfidation curves of the two alloys that were not preoxidized $^{13-14}$. The mass gain and sulfidation rate of the preoxidized $\mathrm{FeCr}$ alloy reveals a rate transition after about $2 \mathrm{~h}$. During this period, the oxide on the alloy surface protects the alloy in the sulfidizing environment. After this initial 'incubation period', the sulfidation rate of the alloy increases. The pre-oxidized $\mathrm{FeCrAl}$ alloys exhibits parabolic sulfidation kinetics and the oxide layer formed during preoxidation protects the alloy for at least $45 \mathrm{~h}$ at $800{ }^{\circ} \mathrm{C}$ in the sulfidizing environment. The $\alpha-\mathrm{Al}_{2} \mathrm{O}_{3}$ layer formed on the $\mathrm{FeCrAl}$ alloy during pre-oxidation is more compact and contains fewer defects compared to $\mathrm{Cr}_{2} \mathrm{O}_{3}$ formed on $\mathrm{FeCr}$ during pre-oxidation. This results in lower diffusion rates of species across the oxide layer. Thus, the incubation period for sulfidation is significantly longer.

The surface of FeCr alloy pre-oxidized and sulfidized at $800^{\circ} \mathrm{C}$ is shown in Fig. 4a. EDS analysis at region 1 in this figure revealed $\mathrm{S}$ and $\mathrm{O}$. The outer layer was found to be rich in $\mathrm{Cr}$ and $\mathrm{Fe}$. Figure $4 \mathrm{~b}$ shows a region on the same specimen where the sulfide layer had spalled. EDS measurements at various regions on this specimen revealed that the $\mathrm{S}$ and $\mathrm{Fe}$ contents decreased in the direction of the sulfide/alloy interface. This reveals that $\mathrm{S}$ does not diffuse

Figure 1. Surfaces of alloys oxidized at $1000{ }^{\circ} \mathrm{C}$ for 4 h. a) $\mathrm{FeCr}$; b) $\mathrm{FeCrAl}$. 


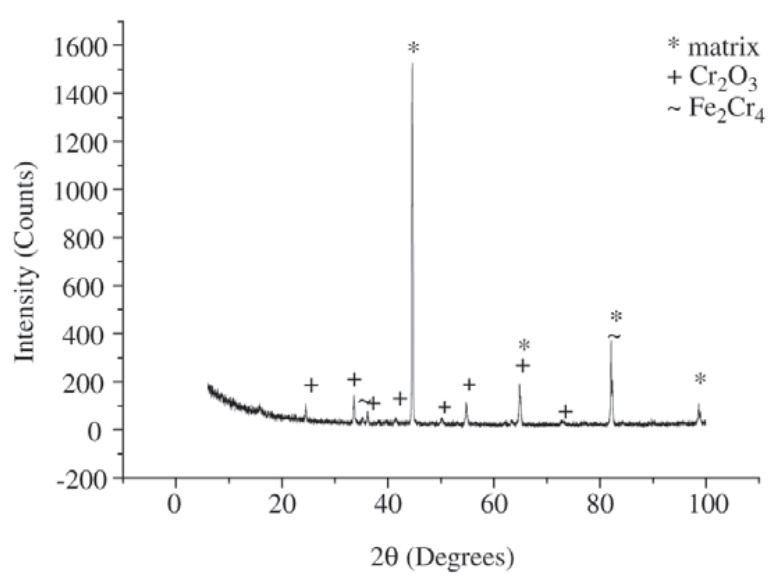

(a)

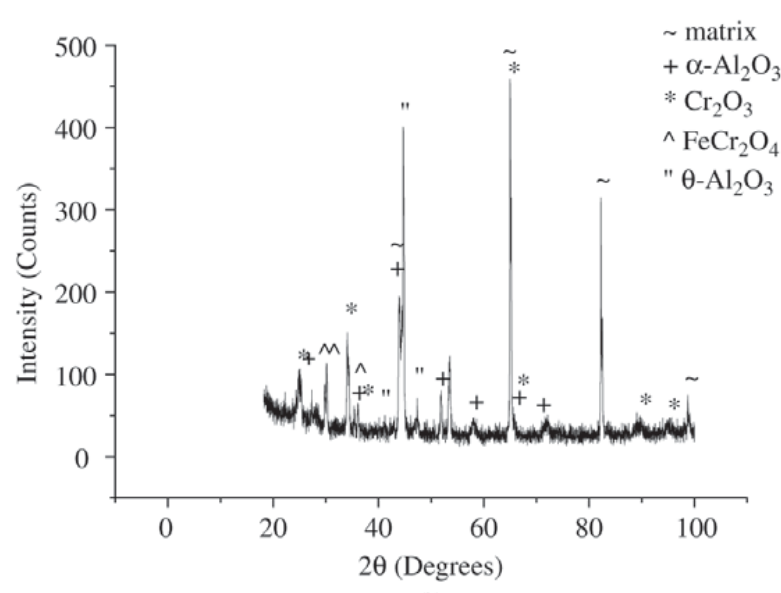

(b)

Figure 2. X-ray diffractograms of alloys oxidized at $1000{ }^{\circ} \mathrm{C}$ for 4 h. a) $\mathrm{FeCr}$; b) $\mathrm{FeCrAl}$.

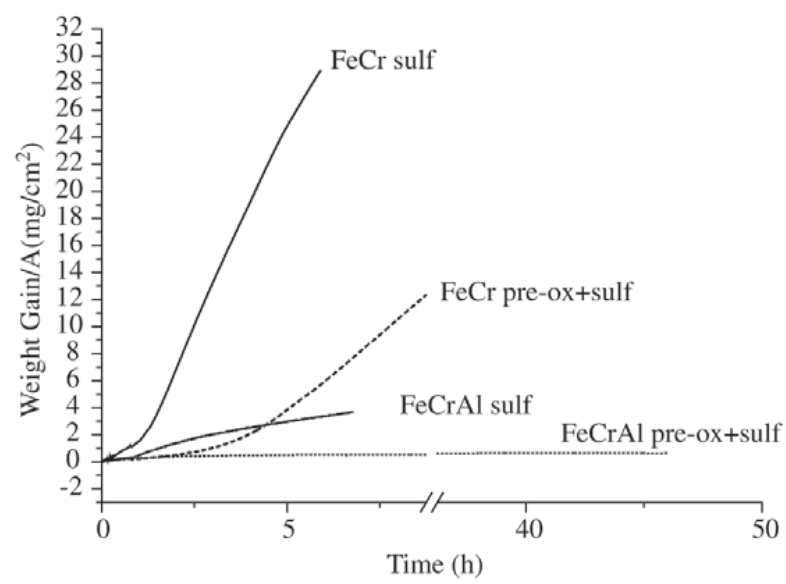

Figure 3. Sulfidation curves of pre-oxidized $\mathrm{FeCr}$ and $\mathrm{FeCrAl}$ alloys at $800{ }^{\circ} \mathrm{C}$.
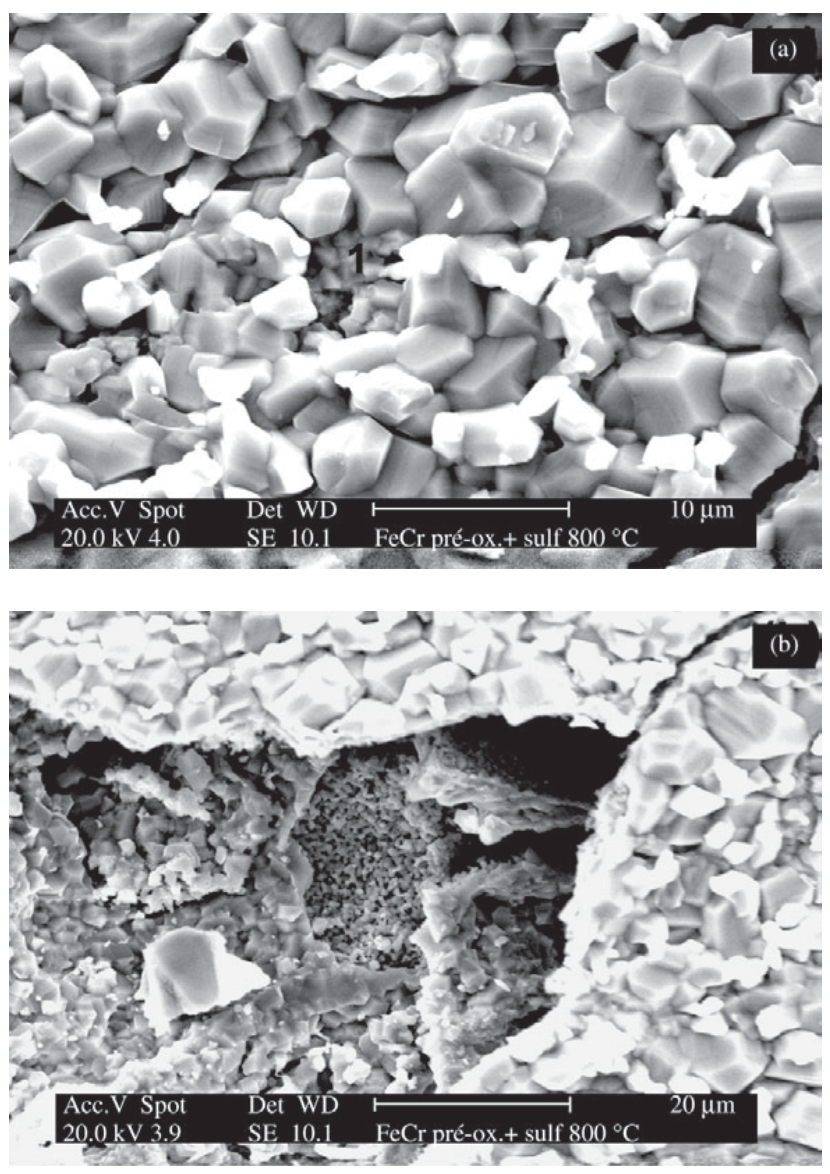

Figure 4. Surfaces of pre-oxidized FeCr alloy sulfidized at $800{ }^{\circ} \mathrm{C}$ in a thermobalance. a) unspalled region; b) spalled region.

easily through the oxide layer and that the sulfides formed preferentially at the gas interface. The $\mathrm{Cr}$ content increased towards the interface with the alloy. The x-ray diffractogram in Fig. 5a reveals the various phases present on the surface of the pre-oxidized and sulfidized $\mathrm{FeCr}$ alloy. Besides the $\mathrm{Cr}_{2} \mathrm{~S}_{3}$ and $\mathrm{FeCr}_{2} \mathrm{~S}_{4}$, chromia formed during the pre-oxidation stage was also detected.

The surface of $\mathrm{FeCrAl}$ alloy pre-oxidized for $4 \mathrm{~h}$ at $1000{ }^{\circ} \mathrm{C}$ and sulfidized at $800^{\circ} \mathrm{C}$ for $45 \mathrm{~h}$ is shown in Fig. 6 . EDS data from a different region of this specimen, shown in Fig. 6b, revealed high Al content and oxygen in region 1, (the back ground). On some regions of the specimen nodule formation was observed (region 2). EDS analysis of a region within this nodule (shown in Fig. 6c) revealed the presence of $\mathrm{Fe}, \mathrm{Cr}, \mathrm{S}$ and some Al. Some sulfide nuclei can be seen at various points on the surface of the specimen shown in Fig. 6a. An X-ray diffractogram of the surface of this alloy is shown in Fig. 5b. Besides $\mathrm{FeCr}_{2} \mathrm{~S}_{4}$, the oxides $\alpha-\mathrm{Al}_{2} \mathrm{O}_{3}, \mathrm{Cr}_{2} \mathrm{O}_{3}$ and $\mathrm{FeCr}_{2} \mathrm{O}_{4}$, formed during pre-oxidation 


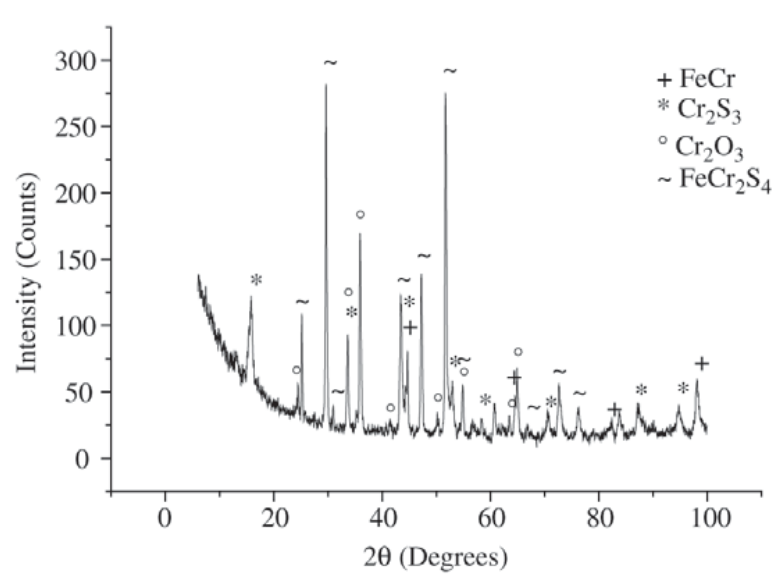

(a)

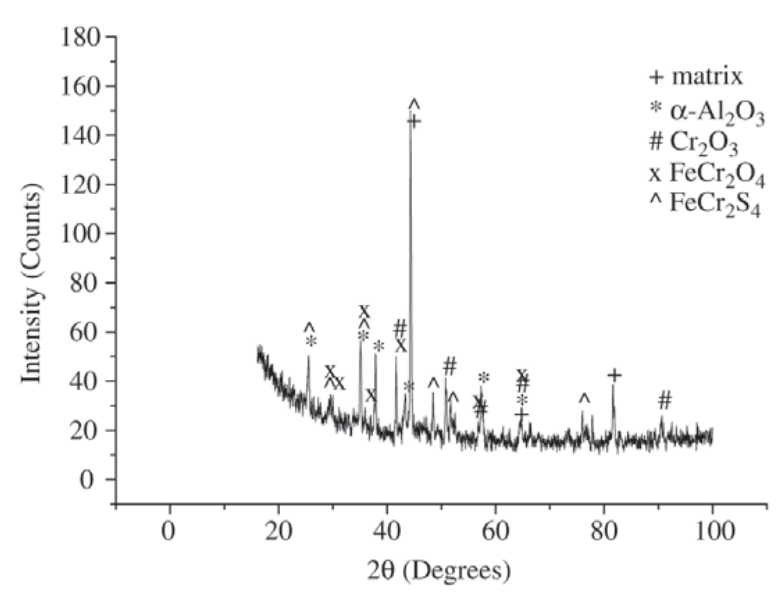

(b)

Figure 5. X-ray diffractograms of alloys pre-oxidized for $4 \mathrm{~h}$ at $1000^{\circ} \mathrm{C}$ and sulfidized at $800^{\circ} \mathrm{C}$ in the thermobalance. a) $\mathrm{FeCr}$; b) $\mathrm{FeCrAl}$.

were detected. These observations are coherent with the model proposed by Stott et al. ${ }^{15}$. Sulfide formation occurred at specific regions and not all over the surface, as observed on the surface of the alloy that was not pre-oxidized. On the basis of this it can be stated that the pre-oxidized alloy would not be resistant to the sulfidizing environment for very long times. Nevertheless, pre-oxidation of $\mathrm{Al}$ containing $\mathrm{FeCr}$ alloy extends the life of components made from this alloy and exposed to sulfidizing environments.

\subsection{Growth sequence of sulfides on pre-oxidized $\mathrm{FeCr}$ and $\mathrm{FeCrAl}$ alloys}

A probable growth sequence of the sulfide layer on $\mathrm{FeCr}$ alloy pre-oxidized at $1000{ }^{\circ} \mathrm{C}$ for $4 \mathrm{~h}$ and sulfidized at $800{ }^{\circ} \mathrm{C}$ is shown schematically in Fig. 7. During sulfidation, $\mathrm{Fe}^{2+}$, $\mathrm{Fe}^{3+}$ and $\mathrm{Cr}^{3+}$ diffuse through the oxide layer as shown in
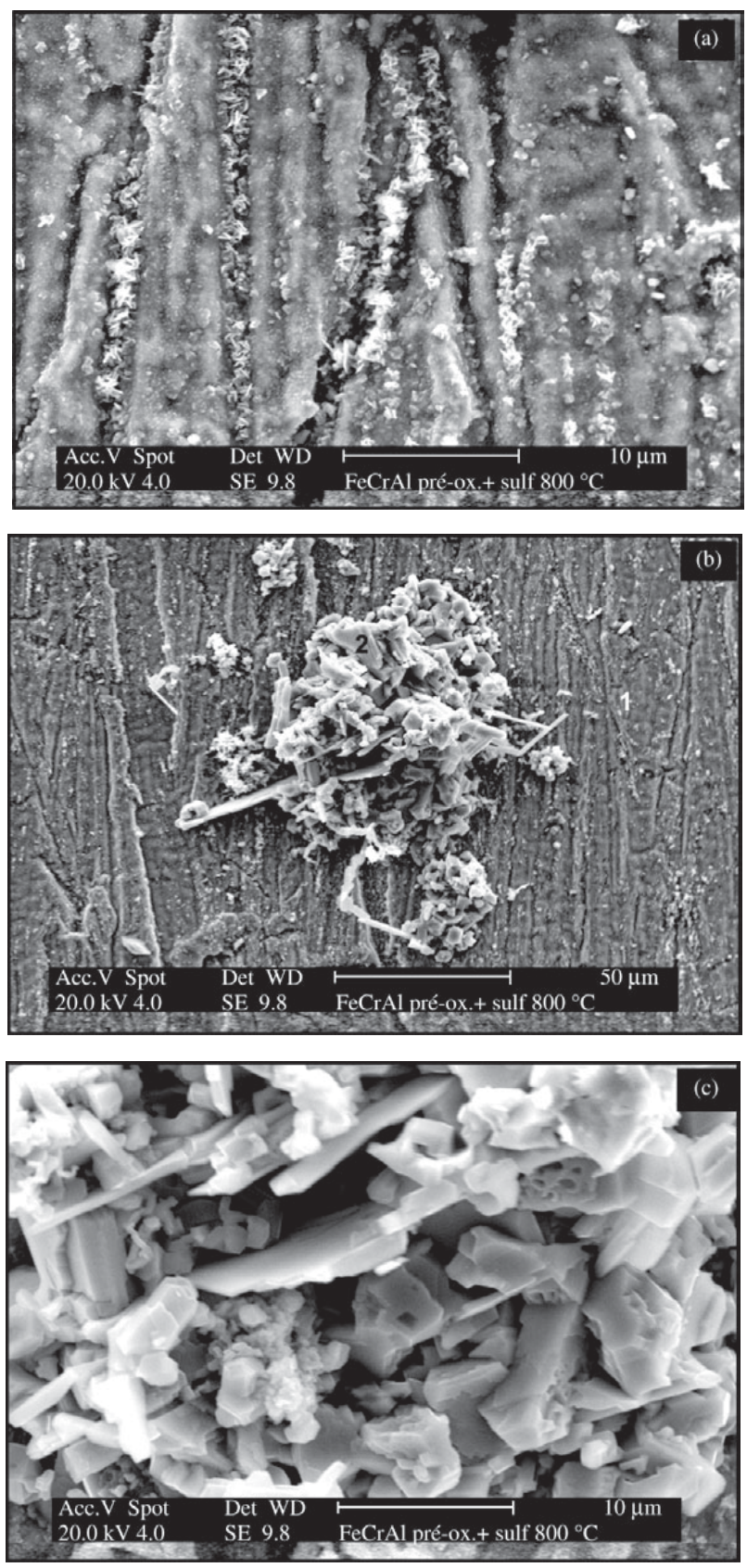

Figure 6. Surface of FeCrAl alloy pre-oxidized and sulfidized at $800{ }^{\circ} \mathrm{C}$ in a thermobalance. a-c) are different regions of the same specimen.

Fig. 7a and sulfides nucleate at the oxide/gas interface (Fig. 7b). With time at temperature, $\mathrm{S}$ diffuses through the oxide layer and encounters the cations diffusing outward, to form sulfides within the oxide layer (Fig. 7c). With continued exposure to the sulfidizing environment, more $\mathrm{S}$ dif- 


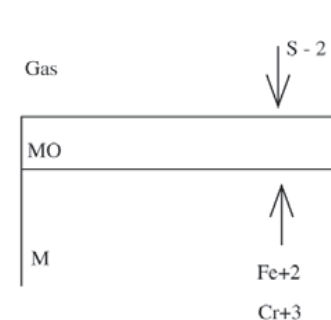

(a)

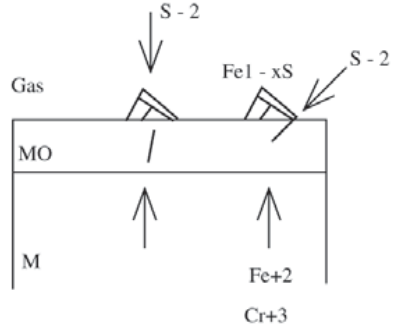

(b)

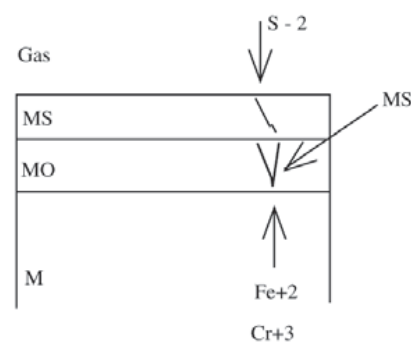

(c)

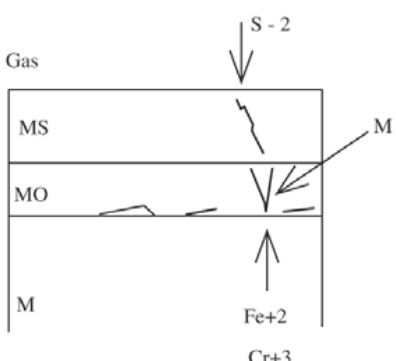

(d)

Figure 7. Schematic diagram showing sulfide layer growth on pre-oxidized $\mathrm{FeCr}$ alloy during sulfidation at $800{ }^{\circ} \mathrm{C}$. a) diffusion of $\mathrm{S}^{2-}$, $\mathrm{Fe}^{2+}, \mathrm{Fe}^{3+} \mathrm{e} \mathrm{Cr}^{3+}$ in oxide layer; b) nucleation of sulfides at oxide/gas interface; c) formation of sulfides in oxide layer; d) growth of sulfides takes place near oxide/alloy interface and ends "incubation period".

fuses through the oxide layer and sulfide growth takes place at the oxide/metal interface as shown in Fig. $7 \mathrm{~d}$ and at this stage the incubation period comes to an end.

Sulfidation of the pre-oxidized FeCrAl alloy can be considered to follow a sequence quite similar to that presented in Fig. 7 for FeCr alloy. For extended periods of exposure the aluminium oxide layer formed on the alloy surface remains unattacked. With time at temperature, $\mathrm{S}$ ions penetrate the alumina layer, reach the alloy surface and react with $\mathrm{Fe}$ and $\mathrm{Cr}$ to form their sulfides. These sulfides push outwards and protrude through the alumina, rather than spread laterally along the oxide/alloy interface. After extended exposure to the sulfidizing environment at $800{ }^{\circ} \mathrm{C}$, significantly longer than that carried out in this investigation, the number of sulfide protrusions could increase until breakdown of protection given by the alumina to the alloy.

\section{Conclusions}

- The $\mathrm{FeCr}$ alloy pre-oxidized for $4 \mathrm{~h}$ at $1000^{\circ} \mathrm{C}$ showed an incubation period of about $2 \mathrm{~h}$ during subsequent sulfidation at $800{ }^{\circ} \mathrm{C}$. After this incubation period, the sulfidation behavior was similar to that of the alloy that had not been pre-oxidized. Sulfide growth occured at the oxide/gas interface.

- Pre-oxidation of the $\mathrm{FeCrAl}$ alloy at $1000{ }^{\circ} \mathrm{C}$ for $4 \mathrm{~h}$ significantly increased its resistance to sulfidation. An incubation period of at least $45 \mathrm{~h}$ in a sulfidizing environment at $800{ }^{\circ} \mathrm{C}$ has been observed.

- The overall improvement in sulfidation behavior indicates that serious consideration can be given towards the use of pre-oxidized alumina forming alloys for applications where extended exposures at low to medium S partial pressures are foreseen.

\section{References}

1. Strafford, K.N.; Datta, P.K. "Progress in the Design of sulphidation-resistant alloys", Corr.Sci.; v. 35, p. 10531063, 1993.

2. Saxena, D.; Prakash, S.; Mehta, M.L.; Saraswat, I.P. "Sulphidation Studies of Fe-15Cr-4Al alloy with $\mathrm{Y}$ and $\mathrm{Zr}$ additions at $850^{\circ} \mathrm{C}$ " in Proceedings of the $10^{\text {th }}$ International Congress on Metallic Corrosion, p. 3495-3506 (Madras, India, 1987).

3. Pillis, M.F.; Ramanathan, L.V. "Effect of yttrium addition on the oxidation and sulfidation behavior of $\mathrm{Fe} \mathrm{CrAl}$ alloy" in Proceedings of the $14^{\text {th }}$ Brazilian Congress on Materials Science and Engineering, p. 33501-33509, 1 CD, (São Pedro, Brazil, 2000).

4. Pillis, M.F.; Ramanathan, L.V. "Effect of yttrium addition on the oxidation and sulfidation behavior of $\mathrm{Fe} 20 \mathrm{Cr}$ alloy at high temperatures" in Proceedings of the $55^{\circ}$ Annual Congress of the Brazilian Association of Metallurgy and Materials, p. 376-382, CD, (Rio de Janeiro, Brazil, 2000).

5. Habazaki, H.; Hon-Yashiki, K.; Ito, K.; Mitsui, H.; A. Kawashima, K. Asami, K. Hashimoto and S. Mrowec "Sulfidation-and Oxidation-resistant alloys prepared by sputter deposition", Mat.Sci. and Eng.; v. A267, p. 267-276, 1999.

6. Mrowec, S. "The problem of sulfur in high temperature corrosion”, Oxid. Met.; v. 44, p. 177-209, (1995).

7. Natesan, K.; Baxter, D.J. "The role of $\mathrm{Zr}$ and $\mathrm{Nb}$ in Oxidation/Sulfidation Behavior of Fe-Cr-Ni Alloys", Report ANL/FE-90/2, Nov. 1990, Argonne National Laboratory, USA, p. 69, 1990.

8. Danielewski, M.; Natesan, K. "Oxidation-Sulfidation Behavior of Iron-Chromium-Nickel Alloys”, Oxid.Met.; 
v. 12, n. 3, p. 227-245, 1977.

9. Schulte, M.; Rahmel, A.; Schütze, M. “The sulfidation behavior of several commercial ferritic and austenitic steels”,. Oxid.Met.; v. 49, p. 33-70, 1998.

10. Ciéslak, J.; Dubiel, S.M.; Zurek, Z. "Investigation of scales resulted from a high-temperature sulphidation of FeCr alloys”,. J. Alloys and Comp.; v. 265, p. 297304, 1998.

11. Zurek, Z.; Gawel, J. "Sulfidation of FeCr binary alloys in $\mathrm{H}_{2} / \mathrm{H}_{2} \mathrm{~S}$ atmosphere at 873-1073 K”, J.de Phys. IV. Colloque C9, supplément au Journal de Physique III; v. 3, p. 327-330, 1993.

12. Colson, V.; Lambertin, M.; Larpin, J.P. "Corrosion of iron based alloys in sulfur containing environments-
Protection by surface treatments" in Proceedings of the International Conference Series, p. 363-367, March 26, 1981, San Diego, California, 1983.

13. Pillis, M.F.; Ramanathan, L.V. "Sulfidation kinetics of $\mathrm{FeCr}$ and $\mathrm{FeCrY}$ alloys”, J. Therm. Anal. Cal.; v. 67, p. 391-396, 2002.

14. Pillis, M.F.; Ramanathan, L.V. "Sulfidation behavior of $\mathrm{FeCrAl}$ alloys" in Proceedings of the XXI Brazilian Congress on Corrosion, (Fortaleza, Brazil, 2001).

15. Stott, F.H.; Chong, F.M.F.; Stirling, C.A. "The effectiveness of preformed oxides for protection of alloys in sulphidizing gases at high temperature" in Proceedings of the International Congress on Metallic Corrosion, v. 2, 1, (June 3-7, Toronto, Canada, 1984). 